\title{
Resistencias y variaciones del ensayo en Argentina. Sobre la teoría de la forma y los ensayos en la prensa periódica
}

\author{
Essay Resistances and Variations in Argentina. On the Theory \\ of the Form and Essays in the Periodical Press \\ Resistências e variações do ensaio na Argentina. Sobre a \\ teoria da forma e os ensaios na imprensa periódica
}

\section{Laura Juárez}

UNIVERSIDAD NACIONAL DE LA PLATA/CONICET, ARGENTINA

Profesora. Licenciada y doctora en Letras. Egresada en la Facultad de Humanidades y Ciencias de la Educación de la Universidad Nacional de La Plata, Argentina. Se desempeña como investigadora adjunta del Consejo Nacional de Investigaciones Científicas y Técnicas (Conicet) y profesora adjunta regular de Literatura Argentina en esa misma Universidad, en la que además dirige desde 2015 el Departamento de Letras. Ha publicado el libro Roberto Arlt en los años treinta (Simurg, 2010), numerosos capítulos de libro y artículos en revistas especializadas. Investiga sobre autores argentinos, literatura argentina y prensa periódica, y dirige proyectos de investigación sobre estos temas. Correo electrónico: laurasjuarez@gmail.com

\section{Miguel Dalmaroni}

Investigador principal del Consejo Nacional de Investigaciones Científicas y Técnicas (Conicet) y profesor de literatura argentina y teoría literaria en la Universidad Nacional de La Plata (UNLP), Argentina. Dirige el proyecto de investigación Archivos fuan fosé Saer (UNLPConicet). Es columnista de www.bazaramericano.com y es miembro del consejo editor de Orbis Tertius. Revista de Teoría y Crítica Literaria. Entre 2009 y 2011 colaboró en la coordinación del Programa Provincial de Lectura en la Escuela de la provincia de Buenos Aires. Ha publicado los libros Una república de las letras (Beatriz Viterbo, 2006), La palabra justa. Literatura, crítica y memoria en la Argentina (1960-2002) (Melusina/ RIL, 2004) y fuan Gelman, contra las fabulaciones del mundo (Almagesto, 1993), y algunos otros en colaboración o como editor. Correo electrónico: dalmaroni@gmail.com

\section{Artículo de reflexión}

Documento accesible en línea desde la siguiente dirección: http://revistas.javeriana.edu.co doi:10.11144/Javeriana.cl20-40.rvea 


\section{Resumen}

El artículo explora dos cuestiones alrededor de ciertas puntualizaciones teóricas recientes sobre el ensayo de los escritores en la crítica argentina. Se trata de dos modos de resistencia de la teoría. La productividad escrituraria y las vueltas al texto de Adorno en los estudios que asumen perspectivas formales sobre el ensayo (o que entienden el ensayo como una forma). Luego, lo que puede leerse como una operación de escamoteo de la crítica y la teoría que se asienta en esa confianza formal a la hora de pensar el ensayo en sus vinculaciones con sus espacios de producción efectivos, es decir, con la escritura de ensayos en la prensa. Se analiza esa inflexión sobre el ensayo un tanto desatendida: el lugar donde los ensayos se publican y qué sucede cuando ese lugar es la prensa periódica y cultural.

Palabras clave: ensayo; prensa periódica; crítica y teoría literaria; Argentina; Borges; Raúl González Tuñón

\section{Abstract}

This article explores two topics related to certain specific theoretical clarifications on the essay made by writers of the Argentinian critique. These are two forms of resistance to theory: scriptural productivity and the return to Adorno's texts in studies which assume formal perspectives on the essay (or understand essay as a form); and, later, what could be seen as an operation to hold back the critique and the theory based on that formal confidence when it comes to think about the essay linked to effective production spaces, that is, essay writing in the press. We analyze that somewhat ignored inflection on the essay: where essays are published and what happens when that place is periodical and cultural press.

Keywords: essay; periodical press; literary critique and theory; Argentina; Borges; Raul Gonzalez Tuñon

\section{Resumo}

$\mathrm{O}$ artigo explora duas questões ao redor de certas observações teóricas recentes sobre o ensaio dos escritores na crítica argentina. Trata de dois modos de resistência da teoria. A produtividade escritural e os retornos ao texto de Adorno nos estudos que assumem perspectivas formais sobre $o$ ensaio (ou que compreendem o ensaio como uma forma). Mesmo, o que pode ser lido como operação de escamoteio da crítica e a teoria baseada em tal confiança formal na hora de pensar o ensaio em suas ligações com os seus espaços de produção efetivos, ou seja, com a escrita de ensaios na imprensa. Analisa-se tal inflexão sobre o ensaio um pouco desatendida: o lugar onde os ensaios são publicados e o que sucede quando esse lugar é a imprensa periódica e cultural.

Palavras-chave: ensaio; imprensa periódica; crítica e teoria literária; Argentina; Borges; Raúl González Tuñón

RECIBIDO: 9 DE JULIO DE 2015. ACEPTADO: 17 DE AGOSTO DE 2015. DISPONIBLE EN LÍNEA: 1 DE JULIO DE 2016

\section{Cómo citar este artículo:}

Juárez, Laura y Miguel Dalmaroni. "Resistencias y variaciones del ensayo en Argentina: sobre la teoría de la forma y los ensayos en la prensa periódica". Cuadernos de Literatura 20.40 (2016): 499-524. http://dx.doi.org/10.11144/Javeriana.cl20-40.rvea 


\begin{abstract}
"El triunfo de la letra es salvaje, más allá de lo que digan los manuales. El sujeto se revela no tanto en la escritura sino en las voces que despierta el texto y en las voces que recorta el lector, represor monofónico de la polifonía. Y en esa lucha, el ensayo es el intento de recobrar la polifonía del texto, desertando quizás del significado e incluso de un significado cristalizado: hacer del texto una insubordinación vocal y abrirse a las múltiples interpretaciones".
\end{abstract}

NICOLÁS ROSA (3)

EL 28 DE enero de 1937, en la sección "Letras españolas", Jorge Luis Borges publica en Sur "Inmortalidad de Unamuno", un ensayo aparecido a propósito de la muerte del escritor y anclado por ello en las circunstancias episódicas del momento presente. Consecutivamente, al otro día y en su espacio habitual del semanario ilustrado El Hogar, edita otro texto sobre Unamuno que no solo vuelve sobre algunas de las obsesiones del primero y ciertos lugares comunes de su crítica ensayística, sino que además se empeña en otras razones y detalles del todo ajenos y ausentes en la primera versión del artículo de Sur. Se trata de la nota titulada "Presencia de Miguel de Unamuno".

Este episodio, aparentemente menor, que involucra la circulación de dos ensayos casi simultáneos sobre un mismo tema y autor, en un escritor paradigmático como Borges quien, como se sabe, acostumbraba maniobrar (Louis) sus escritos, invita a reflexionar acerca de los espacios de producción de los textos ensayísticos en distintos medios de circulación de la letra impresa y permite formular varios interrogantes. ¿De qué manera el ensayo se delimita y construye, con persistencia, en interacción polifónica con los contextos de su publicación? ¿Qué puede leerse sobre el ensayo en ese cruce ineluctable con las zonas de su tránsito y emergencia? ¿Por qué algunas líneas de la teoría y de la crítica, con tenaz apego a ciertas elecciones iniciales, dejan de lado aspectos vinculados a la "realización" concreta de los textos ensayísticos y muchas de las circunstancias específicas del ensayo, el ensayista y lo ensayado? ¿Qué permite leer y priorizar el focalizarse allí? ¿Qué del ensayo se resistiría a ser leído desde ese enfoque?

Procuramos explorar en la crítica argentina dos cuestiones principales a propósito de ciertas puntualizaciones teóricas y consideraciones diversas más o menos recientes sobre el ensayo de los escritores. Se trata de dos modos de la resistencia de la teoría y, a la vez, de resistencias del ensayo a la teoría, a la teorización, al gobierno de su inteligibilidad por parte de una aproximación teórica preferida, recurrente, incluso dominante. 
En primer lugar, la productividad escrituraria, los usos y reutilizaciones, las invariantes y las vueltas renovadas, circulares, recursivas e insistentes al texto de Theodor Adorno en los estudios y esquematizaciones que puede decirse que asumen perspectivas formales sobre el ensayo (o que entienden el ensayo como una forma). En segundo lugar, y estrictamente ligado con lo anterior, lo que puede describirse como cierto escamoteo de la crítica y de la teoría que se asienta en esa confianza, en algún sentido inmanentista y formal (resistencias de la crítica y de la teoría) a la hora de pensar el ensayo en sus vinculaciones concretas con sus espacios de producción y tránsito efectivos o, para ser más precisos, con la escritura de ensayos de autores argentinos, y su publicación, en múltiples medios de prensa (pensamos en la prensa masiva, pero también en revistas culturales o literarias). ${ }^{1}$ Un lugar que podría precisarse como inexcusable y muy prolífico, en muchos casos nodal para la consideración de la producción ensayística en lo que respecta, por lo menos, a la era de la industrialización y la evolución de la cultura impresa en marcos de mayor o menor masividad y circulación escrita de ideas; esta intersección, que coloca la especulación sobre el ensayo sin deslindarse y resistirse a reparar en uno de sus contextos específicos, como lo es el de las publicaciones en diarios y revistas (porque, por supuesto, pueden analizarse otros contextos) se halla escasamente estudiada sobre todo en lo que respecta al ensayo en Argentina.

Interesa detenerse, de esta manera, en esa inflexión de las reflexiones sobre el ensayo un tanto desatendida. El lugar donde los ensayos se escriben o se publican, y qué sucede cuando ese lugar es la prensa periódica y cultural. Se pretende examinar, entonces, la productividad de esas relaciones entre ensayo y crónica, ensayo y prensa, ensayo y revistas, la polifonía que tal indagación propicia (para que, como lectores y críticos, nos seamos represores monofónicos de la polifonía, como sostenía Nicolás Rosa), la intervención ensayística "y de discusión de ideas" en el espacio circunstancial y contingente, muchas veces intensamente misceláneo de las publicaciones periódicas. En este marco, a su vez, es preciso avanzar sobre estas cuestiones con apelación a textos y ejemplos concretos en escritores y casos argentinos, para delimitar de esta manera algunas de las formas y derivaciones del ensayo (dimensiones, variantes, modos particulares de la voz y la escritura) que se generan en ese espacio heterogéneo de la prensa.

$1 \quad$ El artículo se circunscribe en torno de escritores argentinos básicamente, aunque esto podría extenderse a otros ejemplos. 


\section{El ensayo como forma}

Una amplia línea de la crítica y teoría argentinas más o menos reciente y consolidada en los estudios sobre el ensayo parece localizarse, predominantemente, en la confianza de una perspectiva que converge en una particular idea sobre lo formal $;^{2}$ se trata, claro está, de una matriz teórico crítica que, más allá de sus anclajes y ejemplificaciones, piensa el ensayo básicamente como una forma. Esta crítica formal o - en un sentido determinado - formalista, ${ }^{3}$ propicia, a este respecto, un tipo de especulación acerca del modo ensayístico, inclinada en demarcar ciertas constantes más o menos intrínsecas y generales; caracterizaciones constitutivas, potencialidades gnoseológicas, inconsistencias productivas, procedimientos habituales y perfiles ejemplares de funcionamiento del ensayo a propósito de escritores y ensayistas argentinos. En mayor o menor cercanía y vaivén entre los modos del arte (o lo literario) y el saber, el ensayo es depositario aquí de una singular y animada confianza epistemológica, una confianza que parece proceder básicamente de sucesivas relecturas del texto fundacional de Adorno (en la idea de que en el ensayo lo que se ensaya cuestiona los moldes del saber y eso se resuelve en una doble validez frente al objeto ensayado). A partir de este tipo de relectura de Adorno, estas configuraciones teóricas ponen de manifiesto y visibilizan buena parte de las distinciones (distinciones que en mayor o menor medida recaen sobre la forma y lo formal como un modo de escritura de efectos particulares) y representaciones sobre el ensayo. Se deslindan sus variados caracteres y, principalmente, numerosas de sus evaluaciones positivas:

[...] el ensayo sería el género donde las pasiones se convierten en saber, donde lo intransmisible del estilo procura alcanzar la transmisibilidad de los conceptos y a través de ellos la verdad de un objeto, en cuya elección tal vez

2 Cabe aclarar que aunque Liliana Weinberg no trabaja, particularmente, sobre la cuestión del ensayo en la prensa y en las revistas culturales, algunas de las nociones que explicita en su libro Situación del ensayo, contribuyeron para la formulación de esta idea sobre la crítica formal del ensayo en la Argentina (nociones que Weinberg apunta y en las que, por otra parte, no se detiene). Volveremos sobre algunas de sus puntualizaciones, pero interesa señalar aquí lo que la autora denomina como un presente del ensayo que le permite ir más allá de los formalismos: "Una de las preocupaciones que anidan el presente trabajo, [sostiene] es la búsqueda de ese 'tercero excluido' por los formalismos, ese vínculo entre la actitud ensayística y el mundo que consiste en la permanente apelación a un sentido que no está divorciado del acontecer y la evaluación social, así como a al búsqueda de una legalidad capaz de dar cuenta del ensayo por encima y por detrás de sus realizaciones particulares, aunque a la vez sólo resulte entendible a la luz de la inscripción del texto en el mundo" (Situación del ensayo 45; las cursivas son de los autores).

3 Cabe aclarar que al decir formalista, empleamos un sentido bastante llano del término, utilizado aquí casi despojado de historicismos teóricos y técnicos. 
aparezca la verdad única de cada ensayista, su distinción, su especificidad, su enseñanza.

Lo anterior lo anota, por ejemplo, Silvio Mattoni (19-20); y en otro lugar insiste: "El ensayo es la forma por excelencia del pensamiento en lo que este contiene de indeterminado, de proceso en marcha hacia un objetivo que muchos ensayistas nombran como la verdad" (19; las cursivas son de los autores).

En consideración a lo escrito hasta el momento, un estado de la cuestión sobre el tema resulta inagotable en múltiples sentidos, bastante inabarcable y hasta fatigoso, aunque esa inclinación formal de numerosas perspectivas, esa resistencia, puede simplificarse al menos someramente en función de sus reiteraciones e insistencias. Intentamos por ello habilitar cierta reducción de ese gran conglomerado teórico e interpretativo para volver aprehensible una delimitación que si bien podría llegar a ser ciertamente esquemática, permite aproximarse a algunos de sus rasgos y modos habituales de expresión y funcionamiento. Las reflexiones y los escritos (críticos y teóricos) sobre el ensayo se resuelven, entonces, reiteradamente, en el señalamiento y enunciación de varios y determinados aspectos vinculados a la forma del modo ensayístico que se asume de tan compleja circunscripción y heteróclita definición (pero que los textos demarcan y justifican en su forma muchas veces ensayísticamente) y se explicitan y explayan, luego, en el análisis de ejemplos concretos, en casos argentinos ejemplares, en la literatura y en la crítica: como el de Borges, Martínez Estrada, Sarmiento, Piglia, Scalabrini Ortiz, Murena, etc. Pensamos, ciertamente, en muchos de los aportes nucleares sobre el tema, en aquellos que formularon los caracteres y lineamientos del ensayo y los localizaron en el campo de la escritura en Argentina, como los de Alberto Giordano (y algunos de los avances colectivos vinculados a las publicaciones rosarinas, como los dos volúmenes sobre el tema del Boletín), Nicolás Rosa, Silvio Mattoni, Horacio González, entre otros.

En reiteradas oportunidades, a su vez, esta teoría de la forma-ensayo deriva de una lectura cuidadosa y activa de Adorno, que reescribe con matices, aclaraciones, expansiones explicativas, glosas informativas, perspicaces deslices ejemplificadores y estimulantes divergencias su artículo proteico y fundacional, al cual se retorna una y otra vez. Este proceder es indudable, por ejemplo, en muchas zonas del libro de Silvio Mattoni, Las formas del ensayo, donde esto se manifiesta ya desde el título. Efectivamente,junto con cierta apuesta narrativa que se solventa en una explicitación del texto de Adorno, la primera parte de ese libro se vuelve una paráfrasis lúcida y ampliada, una lectura sutil de "El ensayo como forma" y otros trabajos de Adorno que también se suman en las definiciones sobre el tema. 
A la enunciación formal de los caracteres del ensayo aquí se anexan la aclaración del modo de interpretación de Adorno y de muchos de sus conceptos polémicos e intrincados. En el penetrante y sugerente prólogo de Nicolás Rosa al libro que compila varios artículos sobre el ensayo - ligado ahora a la vertiente de lo nacional-, Historia del ensayo argentino. Intervenciones, coaliciones, interferencias, el impulso crítico, en algunos sentidos, parece moverse en una dirección similar. Rosa entiende el ensayo en su carácter de "matriz retórica" y por ello elocuente de posibilidades que invita al cuestionamiento de los andariveles del saber estigmatizado. Por ello, no solamente se propone "describir e interpretar históricamente la forma ensayo" en relación con la nacionalidad (10), sino que además sostiene que el ensayo hace surgir una "experiencia" - que él llama praxis escrituraria"-, "algo más de lo que se dice cuando se dice algo" (23; cursivas de los autores). Giordano, por su parte, en cuanto sostiene que el ensayo constituye aquello que permite ir más allá de la razón, "exceder el saber" al ser "ficción interpretativa" y "mantener su poder de inquietud" (72, 73 y 134), parece asumir una y otra vez esa perspectiva adorniana pergeñada en el texto pionero y ahora revisitada para pensarla en casos argentinos concretos y en ensayistas para cuyo examen el enfoque de Adorno parece apropiado e incluso poblado de afinidades.

De esta manera, aquello que la crítica argentina retoma una y otra vez de la impronta adorniana parece remitir casi siempre a esa capacidad de interrogación que procura y a la que dispone formalmente el ensayo, en términos de Adorno. A medio camino entre el conocimiento científico y el arte y la literatura (y en esto, como se sabe, Adorno se distancia de la perspectiva de Luckács para quien el ensayo es "forma artística"), a la vez que el ensayo goza para el pensador alemán de una potencia retórica, implica, "siempre", una discusión de ideas y se sitúa así en el terreno de la especulación discursiva. Es más, parte de aquello "preformado culturalmente" —es una derivación de un sujeto sobre un objeto que "penetra lo que se esconde como ob-

4 Dice Giordano, refiriéndose a los ensayos Oscar Masotta, otro de los modelos de su crítica y propuesta adorniana: " $[\ldots]$ no hay crítica literaria sin la experiencia de sus límites $[\ldots]$ la crítica, si es literaria, si consigue recomenzar [...] la inagotable búsqueda de la literatura, solo se hace posible cuando experimenta el desfallecimiento de sus poderes, la imprevista metamorfosis de las fuerzas que la animan" (136).

5 Adorno y Lukács coinciden en que el ensayo es siempre revisión de algo ya dado y preformado culturalmente. En este sentido afirma Lukács muy elocuentemente: "[...] el ensayo habla siempre de algo ya formado, o por lo menos de algo que en alguna otra ocasión ha sido; corresponde a su esencia no sacar de la nada nuevos objetos, sino solamente ordenar de nuevo los que en alguna ocasión tuvieron existencia. Y por limitarse a esta nueva ordenación, sin crear de lo informe nada nuevo, está obligado a expresar continuamente la 'verdad' sobre ellos, y a buscar la manera de exteriorizar su esencia" (267-268). 
jetividad detrás de la fachada"(13) - y va más allá. Por este motivo puede decirse que su forma habilita un pensamiento que trasciende eso "que se encuentra ya pensado en lo dado". Ciertamente, hay, para Adorno, un plus más que significativo en el ensayo (13), y ese excedente se expresa primordialmente en la crítica que este permite del "sistema científico": el ensayo muestra un saber histórico y situado, no está de acuerdo con que el orden de las cosas sea el mismo que el de las ideas; ${ }^{6} \mathrm{el} \mathrm{"ensayo} \mathrm{tiene} \mathrm{en} \mathrm{cuenta}$ la 'no identidad' aun sin expresarla siquiera. Es radical en el 'no radicalismo', en la abstención de reducirlo todo a un principio, en la acentuación de lo particular frente a lo total, en su carácter fragmentario" (19). Por ello, en el pensamiento de Adorno, es un ensayo todo lo que implica una forma excelsa y cuestionadora de las formaciones espirituales: "es la crítica por excelencia" e "inmanente" "de nuestro espíritu" (30): "escribe ensayísticamente el que compone experimentando, el que vuelve y revuelve, interroga, palpa, examina, atraviesa su objeto con la reflexión, el que parte hacia él desde diversas vertientes y reúne en su mirada espiritual todo lo que ve y da palabra a todo lo que el objeto permite bajo las condiciones aceptadas y puestas al escribir" (28). A este respecto, sostiene Silvio Mattoni:

$[\ldots]$ asumir la posición del ensayo significa siempre por su negatividad con respecto a las formas institucionalizadas del conocimiento y a los cánones de su trasmisión, trasformarse en crítico de la cultura [...]. El ensayo procede de una forma metódicamente ametódica ya que es en sí una crítica de los métodos y de sus condiciones de posibilidad, operada desde la óptica no absolutizable de un sujeto y de su relación con lo que la cultura le destina como saber. [...] Por lo tanto, siempre inseguro en cuanto se mantiene afín a la experiencia abierta y móvil, el ensayo no se atiene a la norma establecida de la certeza libre de duda y no solo se limita a prescindir de ella, sino que también denuncia ese ideal como sostén del statu quo [...]. La búsqueda de los orígenes ahistóricos de la ciencia es negada por el ensayo, cuyo gesto fundamental sería la cita, la derivación infinita de unos textos en otros. (20,25 y 26)

Como puede verse manifiestamente en la cita de Mattoni, este ánimo optimista originado en torno a las potencialidades que se involucran en el ensayo como forma adorniano $-\mathrm{y}$ sus particulares ventajas en cuanto instrumento crítico de la cultura-, organiza lo que estas perspectivas formales retoman y reivindican. Esta

6 Dice Adorno: "el ensayo denuncia sin palabras la ilusión de que el pensamiento pueda escaparse de lo que es thései, cultura, para irrumpir en lo que es physei, naturaleza, atado por lo fijado, por lo confesadamente derivado, por lo formado, el ensayo honra a la naturaleza al confirmar que ella no es ya el hombre" (21). 
convicción epistemológica constituye, por ello, el doblez de una apuesta por el método que el ensayo promueve; es decir, se trasunta en una confianza metodológica (o seguridad en lo "metódicamente ametódico") que los teóricos y críticos del ensayo destacan una y otra vez y que está en la base de lo que no termina de cuestionarse, discutirse pero sobre todo de problematizarse tanto en autores como Mattoni, Giordano o Rosa, como en las certezas que parecen subyacer en textos como el de Horacio González. La productividad teórica y metodológica le permite a Giordano, por ejemplo, explicar y justificar su modo de leer, su forma de hacer crítica literaria; también a Rosa y a Mattoni en varios sentidos. La misma tesis de la productividad sostiene, a su vez, las peculiaridades escriturarias y la versatilidad argumentativa y expositiva del libro de Horacio González. Se trata, entonces, de una confianza dual (en el método y en el saber que posibilita) que contribuye de diversos modos y en diversos textos especulativos a prever y ponderar en muchos casos cierta asistematicidad, cuyo valor estaría garantizado por la "forma genérica", metódicamente ametódica, sistemáticamente asistemática y productora de pensamiento crítico posibilitado por el ejercicio del ensayo.

Más allá de las realizaciones y los innegables hallazgos de esta teoría críticoformal, la perspectiva parece haber ido acompañada de algunas resistencias; pueden enunciarse al menos dos. En principio, el enfoque adorniano en Argentina parece cerrar la consideración sobre el ensayo a los casos más formales o a cierto conjunto de ensayos; quedan afuera del campo de estudio, de este modo, muchos textos argentinos que solemos considerar ensayos o dar como tales, aun de los propios ensayistas analizados, como algunos de Jorge Luis Borges, que hasta cierto punto no entrarían en la caracterización del "ensayo como forma". 7 Segunda resistencia: las posiciones críticas mencionadas, a su vez, no suelen salir con demasiada frecuencia de los aspectos de la "forma" como dimensión interna o textual y de un análisis de sus efectos sobre los saberes y las posibilidades del pensar. Tales

7 La fuerza de Adorno en la especulación sobre Borges ensayista parece impedir, en reiteradas oportunidades, reflexionar sobre muchas de las desviaciones y separaciones borgeanas del ensayo como forma o sobre aspectos que escapan y se distancian de esta consideración y que se vinculan con otros impulsos y lineamientos. Es interesante considerar aquí que Sergio Pastormerlo, al trabajar un corpus más completo de textos especulativos de Borges, se sale de la denominación "ensayo" para lo que asume como la "crítica" de Borges y esto le permite una apertura más problematizadora y más abarcativa del conjunto de obras que se va a explorar. Lo que interesa indagar aquí, a partir de esto, es la potencialidad crítica que pudiese esperarse - en beneficio de una teoría del ensayo más densa o menos unilateral- si a ese vasto corpus que Pastormerlo elige llamar "crítica" volvemos a nombrarlo con la noción de "ensayo". Agradecemos a Juan Agustín Mucci, quien al hacer un comentario al respecto, contribuyó a la formulación de algunas de estas cuestiones. 
perspectivas soslayan y hasta evitan otros aspectos del ensayo como problema, incluso manifestando a veces - deliberadamente o no- cierta displicencia respecto de su importancia. Nos referimos, sobre todo, a las relaciones que la escritura y la voz del ensayo (nada menos) establecen con los contextos de su publicación y circulación. Esas relaciones (a semejanza de lo que se atribuye a la forma del ensayo en su vinculación con con el saber) son irremediablemente tensas y productivas, y de ningún modo simples y reproductivas. Por supuesto, las escrituras ensayísticas oponen particulares resistencias y ejercen presiones y tensiones ante los límites y las condiciones, las expectativas y presupuestos que les presentan las revistas, los diarios, las colecciones o editoriales en que se publican. Pero, precisamente, lo hacen, y en términos de las escrituras y sus efectos, eso significa que el ensayista toma decisiones retóricas, sintácticas, tonales o argumentativas como reacción, réplica, desafío, negociación parcial, desvío, ignorancia o distracción más o menos deliberada respecto de tales condiciones, expectativas y contextos.

Si "el ensayo como forma" dio curso a una comprensión crítica innegablemente productiva, parece difícil al mismo tiempo no advertir que su empleo como modelo teórico hipotético o matriz de lectura no se caracterizó precisamente por problematizar estas dimensiones en las que (creemos) numerosos ensayos se resisten a la teoría. Y esas resistencias no problematizadas (o escasamente consideradas) que el ensayo interpone entre su escritura y los contextos también lo conforman y lo configuran, lo incitan a inventar transformaciones de sí y, por lo tanto, de los lectores y diarios de las revistas en que se publican.

\section{Preliminares}

Ahora bien, además de las concepciones teórico-críticas ya comentadas, antes de reflexionar sobre las diferentes implicancias de pensar el ensayo en su circulación e intersección con las publicaciones de prensa masiva y cultural, es preciso mencionar, principalmente, los aportes sobre el tema de Jaime Rest y las investigaciones de Liliana Weinberg.

El cuarto en el recoveco, de Jaime Rest, un texto cronológicamente muy anterior a las perspectivas adornianas analizadas, constituye uno de los primeros libros que ilustran los alcances y manifestaciones del ensayo en Argentina. Este sugerente estudio, antes que enfocarse en la cuestión de la forma - pues ve al ensayo como aquello que carece de una forma propia y es asimilable a diferentes modos de la prosa de ideas y la especulación) - ${ }^{8}$ considera la producción ensa-

8 Dice Rest, a este respecto: "El ensayo por lo general se propone describir o interpretar una determinada cuestión valiéndose de una determinada actitud expositiva o elocuente que 
yística y a los ensayistas en diferentes momentos y en relación con algunos de los circuitos de su tránsito y producción, como lo son los artículos periodísticos de los diarios y los ensayos que aparecieron en revistas y magazines de Argentina. En esa línea y no sin cierta polémica, le dedica un capítulo al análisis de las aguafuertes porteñas de Roberto Arlt (que Rest lee como ensayos), ${ }^{9}$ con una intención clara: parte de la tesis de que es el periodismo uno de los "vehículos naturales" de la "difusión" y "proliferación" del ensayo, e incluye el artículo de costumbres como una de las formas en las que, con el avance de la prensa moderna y la alfabetización, se generalizaron y se diversificaron las características de este género. Esto le permite a Rest considerar "la función del artículo periodístico en el cuadro general de nuestro ensayo" y determinar "a través de la obra de Arlt, la importancia que poseía en su intento de indagar las manifestaciones de la vida urbana" (73). De este modo, en la prensa periódica, el ensayo se inscribe también en los medios de circulación masiva y la consideración de Arlt posibilita al autor leer las aguafuertes porteñas como el testimonio de Buenos Aires convertida en ciudad cosmopolita, pues "en el ejercicio de esta forma particular del ensayo que es el artículo periodístico, Arlt logró trazar un intrincado y minucioso cuadro de la realidad porteña en un período clave de nuestra evolución contemporánea" (68).

Además del periodismo, en el cuarto capítulo de su libro, Rest se propone referirse "a otra variedad del ensayo cuyo soporte material, cuya vía de difusión ha estado principalmente en la revista literaria", y así es como inicia su indagación sobre Borges. Porque si para el autor "ha sido una gran fortuna [...] haber contado [en Argentina] con unas pocas de estas revistas que han perdurado a lo largo de nuestro siglo", son estas publicaciones las que "han dado cabida a la producción de algunos de nuestros más significativos cultores de lo que denomino el 'ensayo especulativo". Es decir, si bien Rest no va más allá de una demarcación de líneas de circulación y visualización del ensayo, y no se detiene en analizar su funcionamiento específico y peculiar, su perspectiva considera que en las revistas literarias y en los diarios se propició su surgimiento y evolución. De esta manera, aunque Rest no se detiene en leer las productividades explicativas y plurales del cruce y la concurrencia con la prensa periódica (en cuanto al ensayo, el ensayista y lo ensayado), presta atención al lugar donde los textos ensayísticos se producen. Su aporte permite, de

carece de una forma enteramente propia, capaz de diferenciarlo con claridad de la prosa en sí misma" (15).

9 En un trabajo anterior se desarrolló una pequeña reflexión en torno a la consideración de las aguafuertes porteñas como ensayos y también la de ciertos textos finales de Arlt, publicados ya no en el marco de la columna "Aguafuertes porteñas" y aparecidos a propósito de la novela (véase: Juárez, "Arlt y la polémica"). 
este modo, una circunscripción y enunciación del problema en una línea diferente de las perspectivas que - por formales o por pensar el ensayo desde el punto de vista genérico de la hibridez constitutiva de la crónica - soslayan muchas variables significativas a la hora de dar cuenta de la capacidad polifónica del ensayo y de su indefinición que siempre suele volverse explicativa. Tal es el caso de enfoques como el de Jean Starovinsky, que considera que la crónica periodística suele ser un subgénero del ensayo sin indagar en profundidad en la cuestión; o Susana Rotker, quien deslinda el ensayo en los diarios en sus vinculaciones con la crónica como un modo de la hibridez. En los dos últimos casos, el efecto de tales lecturas parece reducir la productividad del ensayo al cruce de lo misceláneo y a la heterogeneidad genérica de la crónica periodística.

También fuera de las conceptualizaciones de la crítica argentina, pero colindante con ella, aparecen, en cambio, algunos precedentes en ciertas lecturas como la de Liliana Weinberg y sus trabajos teóricos y críticos sobre el ensayo, los ensayistas argentinos y latinoamericanos. Weinberg reflexiona muy acertadamente sobre quiénes son ensayistas y muestra de qué modo es muy significativo pensar el lugar del que enuncia y la construcción del nombre propio en relación con los enunciados expresados y en sus vínculos con el posible lector, pues "el punto de encuentro entre un ensayista y su público se debe, en buena medida, a que el lector se reconoce y confía en quien escribe; el ensayista no es un descastado, un paria ni un recién llegado al sistema literario: ocupa ya un lugar estratégico en el campo intelectual". ${ }^{10}$ Además y fundamentalmente, se propone leer lo que denomina el presente del ensayo, es decir, los ensayos vinculados con su aquí y ahora escriturarios. Como indica Weinberg, mucho se ha estudiado a este respecto, aunque falta una consideración que piense al ensayo justamente en ese presente que, en muchos sentidos, lo constituye:

El lugar del ensayo es también un espacio ligado a un aquí y un sitio concreto, a la vez que escenario construido por el propio texto que evoca el momento de la enunciación.

El aquí del ensayo se corresponde con el ahora, con la inscripción del presente: se trata de un lugar que está a la vez marcado como no neutral ni general y conserva sus señas de origen, pero también como un lugar privado que busca inscribirse en el espacio público y alcanzar una representación del mundo. (Situación del ensayo 75)

10 Son palabras de Saítta ("Modos de pensar lo social" 107-146). El texto de Liliana Weinberg al que se hace referencia es El ensayo, entre el paraíso y el infierno (22). 
Efectivamente, sus investigaciones abren un campo que si bien la autora no ha desarrollado en relación con la prensa y las publicaciones periódicas, permite identificar, de todos modos, la representación de ese espacio constituido por el ensayo en el texto en sus relaciones y "articulación dinámica" con el campo de discusiones en que se inserta y en la consideración de uno de sus rasgos más evidentes, "curiosamente desatendidos": el "despliegue" ensayístico de un sujeto identificable y reconocido en el campo cultural "a partir del tiempo presente" (19). A este respecto, sin embargo, cabe aclarar que una consideración de las relaciones del ensayo con el presente no puede desentenderse del problema de "lo inactual" e incluso de "lo intempestivo" como figuras que describen precisamente el modo en que la literatura se relaciona con la actualidad, en la línea de las conceptualizaciones de "lo contemporáneo" propuestas por Agamben. La cuestión se vuelve relevante aquí porque "lo contemporáneo", así como "lo inactual", nos obliga a estudiar qué movimientos da la escritura del ensayo en sus tensiones variables con el actualismo constitutivo de la prensa periódica.

\section{Espacios del ensayo}

Es posible delimitar dos cuestiones entrelazadas con las cuales pensar la productividad de reconsiderar los ensayos en cruce y confluencia con los sitios de su emergencia y circulación. Efectivamente, la polifonía y multiplicidad a la que invita el ensayo se potencian y extreman si se analizan los espacios de los diarios y de la prensa cultural en los que esos ensayos se publicaron. Más que de un cierre contextual, lo que aquí se vehiculiza permite hacer visibles de modo concreto y contundente numerosas maniobras e irresoluciones de la escritura que pueden ser más que relevantes a la hora de estudiar las vacilaciones reflexivas e intelectuales en el ensayo de un escritor, las definiciones temáticas, las configuraciones autorales, las elecciones retóricas y sus efectos, etc.

Es más, si los textos ensayísticos se han interpretado como un entramado retórico y especulativo que permite visualizar la obra de un autor de un modo inédito (y en ese sentido van muchas de las aseveraciones de Giordano) y mostrar así, de muchas maneras, sus contradicciones explicativas y reveladoras, el ensayo en la prensa masiva, miscelánea y en las revistas o magazines, en cuanto evidencia lo circunstancial, contingente y accidental que reiteradamente allí está implícito, favorece o lleva a un extremo esas incertidumbres, titubeos e inconsistencias significativas de la escritura ensayística. Las circunstancias y los contextos que se asocian a los espacios de producción del ensayo ponen de manifiesto de modo sutil, pero concreto, convincente y también intenso, lo preformado de las definiciones escriturarias y autorales y muchas de sus implicancias culturales; las 
oscilaciones e indecisiones constitutivas de la identidad del escritor (Heinich), las fluctuaciones de la enunciación de ideas en el ensayo. A continuación se intenta poner en juego estas conceptualizaciones sobre los ensayos en la prensa masiva y cultural con dos ejemplos concretos: el caso de Raúl González Tuñón, en Crítica, cuando ensaya sobre la guerra del Chaco Boreal, y el mencionado al inicio de Borges en la escritura y reescritura de la nota sobre el mismo autor en Sur y El Hogar.

\section{Raúl González Tuñón: ensayos en el diario}

En el ya clásico e insistentemente citado capítulo de Beatriz Sarlo sobre Raúl González Tuñón, publicado en Una modernidad periférica a fines de la década de los ochenta, refiriéndose a las peculiaridades que destacan al poeta en el contexto de la vanguardia martinfierrista, Sarlo afirmaba: "[González Tuñón] incorpora productivamente la dimensión política en su escritura y construye, en ella, un nuevo tipo de escritor, viajero y testigo: no solo el que mira e inventa, sino el que juzga y agita". Más adelante, agrega: "ninguna de estas operaciones puede ser entendida al margen de los cambios inscriptos en el proceso de modernización cultural y urbana" (155). Se refería, claro, al periodismo profesional consolidado en diarios como Crítica y El Mundo que "produce transformaciones"; asimismo "en las condiciones de producción de su literatura". A estas aseveraciones de Sarlo (también examinadas y expandidas en algún punto en los trabajos de Sylvia Saítta sobre Contra) es posible sumar esta otra hipótesis complementaria: es dable esperar que la producción de transformaciones - como ya apuntamosno sea unidireccional. Es decir, no es solo que el periodismo profesionalizado determina cambios en lo literario; a la vez, el ejercicio del ensayo (de la literatura, en fin) en esos contextos de prensa parece tocar, desacomodar, desplazar y modificar también los límites de esos géneros y soportes masivos. Ya se ha sugerido, y sin dudas tiene algo de paradojal: si fuera el caso de que esta hipótesis sea la preferible - para decirlo con Barthes o a la luz de casos como los de Arlt o Borges, que la literatura que llamamos ensayo le hace algo a los límites de la prensa donde se publica-. Si tal hipótesis, decíamos, mantiene su capacidad crítica, entonces debería merecer la atención de los críticos del "ensayo como forma". Ya que estamos hablando de las potencias del ensayo, aquí no tanto respecto del saber y del pensar, sino más bien de las codificaciones y condicionamientos de otra zona de la cultura y lo social: la prensa.

Estas consideraciones permiten mostrar una interesante y ágil productividad si se ponen en correlación con uno de los viajes reales y concretos que González Tuñón realizó y los textos ensayísticos, periodísticos y literarios que 
ese viaje suscitó: nos referimos a sus corresponsalías como enviado "estrella" de Crítica a la guerra del Chaco Boreal, en 1932. En estas notas González Tuñón ensaya e introduce en su periodismo distintos modos de su labor escrituraria: las corresponsalías son textos bien misceláneos que a cierta pretensión ficcional y al itinerario de viajes anexan en diversos momentos el ensayo lúcido y cierto tono panfletario y político sobre la guerra del Chaco, sobre todo en las primeras y las últimas entregas. En estos ensayos y misceláneas se modulan, con ciertas peculiaridades, distintas formas de lo que podría leerse como un cierto pasaje en su itinerario intelectual (literario, profesional y de artista vanguardista y social): el pasaje en los textos hacia un viajero-testigo, escritor de acción política, militante y antibelicista. Sus notas ofrecen, en este sentido, inflexiones que nos reenvían a las figuraciones del poeta comprometido que aparecen insistentemente en un tiempo posterior de su producción, en sus publicaciones sobre España y la Guerra Civil española. Interesa considerar, a este respecto, algunos de los modos de lo que se pretende leer como entre aprendido y ensayado en el periodismo de Crítica, aquello que no se puede leer (o difícilmente se puede leer) si consideramos los textos aisladamente del contexto de su inscripción. Analizaremos ciertas opciones escritas y fluctuaciones escriturarias que allí se inscriben en relación con el testimonio del corresponsal y el ensayo-crónica de viajes del diario. Los textos de Chaco muestran, en el contexto del diario Crítica, algunos vaivenes y tensiones de Raúl González Tuñón y cierto peculiar acercamiento al Partido Comunista (recordemos que Tuñón se afilia decididamente al partido en 1934). La guerra del Chaco referida en las corresponsalías de Tuñón invita a examinar, así, algunas de las claves de su viraje político, un aprendizaje del cronista que en años subsiguientes otros textos expanden y profundizan. Una de las primeras manifestaciones, entonces, del viajero de acción política y del intelectual comprometido.

Con titulares impactantes y atrayentes y ocupando una página completa del vespertino Crítica (segunda época), aparecen entre el 19 y el 28 de octubre de 1932 una serie de "crónicas ilustradas" sobre la guerra del Chaco paraguayo (desatada entre 1932 y 1935), publicadas por Raúl González Tuñón. Se trata de una sucesión de diez entregas y catorce "capítulos" que salen a la luz continuada y sucesivamente en el diario en una sección enmarcada con el llamativo e inclusivo título de "Crítica en el infierno del Chaco" ${ }^{11} \mathrm{El}$ despliegue técnico que sostiene la

11 Los años veinte son un momento en que muchos escritores vanguardistas,y más específicamente, martinfierristas, ingresan a staff de redacción del diario de Natalio Botana, como el propio Raúl González Tuñón, su hermano Enrique, Jorge Luis Borges, Nicolás Olivari, Sixto Pondal Ríos, Luis Cané, Horacio Rega Molina, Pablo Rojas Paz, Cayetano Córdoba Iturburu (Saítta, Regueros de tinta). En el caso de González Tuñón es de destacar que a su labor como escritor y 
búsqueda del registro fotográfico y del documento escrito, visual e informativo va en pos de sustentar una "veracidad" que, en principio, en 1932, el escritor, no busca manifiestamente ni discutir ni investigar: el apoyo enfático de Crítica en esos años al Paraguay frente a las políticas empresariales de Bolivia. Y, ciertamente, González Tuñón parece orientarse a confirmar en Chaco aquello que ya sabe antes de partir, su denuncia de los capitalistas frente a lo que se asume como una guerra fraticida:

Estas palabras mías, estas cosas que ví y que oí en el Chaco [...] no han sido escritas para exaltar la guerra, que es siempre un asesinato. Al contrario, han sido escritas para proclamar todo el asco y todo el horror de la guerra. Paraguay no tiene la culpa del drama que en estos instantes se desarrolla en los campos trágicos de los fortines, ni tampoco los infelices soldados bolivianos, que ni saben por qué pelean. De mi relato surgirán los culpables: los capitalistas de Bolivia, los agentes de las empresas petroleras y armamentistas que animan la enfermiza y delirante mentalidad de un grupo de personajes sombríos que han hecho incurrir a Bolivia en lo que, en lenguaje diplomático internacional, se llama vandalismo. ("Sobre los techos de Asunción" 3)

Interesa destacar aquí el modo en que el escritor periodista, al esbozar su sentenciosa crítica hacia lo que considera una "guerra fraticida" "de interés imperialista" (que en sus notas remite casi exclusivamente a la empresa petrolera boliviana Standard Oil, como se ve), muestra un acercamiento oscilante (con vaivenes, tensiones y diferencias) a algunas de las manifestaciones públicas sobre la guerra del Chaco realizadas por los comunistas, ${ }^{12}$ en un movimiento que pone en cuestión, a su vez, subrepticiamente, su apoyo a Paraguay, expresado inicialmente de manera rotunda y en varias zonas de sus "entregas" como continuación de los objetivos que movían el viaje de Crítica.

En efecto, tal como ha estudiado Juan Luis Hernández, muchos textos comunistas (Hernández analiza, entre otros, los que se publican en La correspondencia

poeta se suma una intensa y continuada actividad como periodista en diversos medios gráficos a lo largo de su carrera. Desde 1925, Tuñón comienza a trabajar en Crítica y las formas de su colaboración son bastante disímiles y misceláneas. Para un panorama somero y descriptivo de su participación en la prensa y también en Crítica puede consultarse el libro de Germán Ferrari, aunque no se trabaja allí con fuentes primarias. Cabe aclarar que los textos de González Tuñón sobre la guerra del Chaco, de enorme valor documental y literario, aparecidos en Crítica en octubre de 1932 e incorporados en el examen de este artículo, nunca fueron publicados en libro (ver la bibliografía al final donde se detalla la lista de esas colaboraciones y textos aquí considerados). Véase Ferrari y Juárez.

12 Para la lectura del conflicto bélico que realizan los comunistas véase: Hernández. 
Sudamericana) leían el conflicto en relación con los intereses imperialistas de Bolivia y Paraguay (la Standard Oil boliviana, ligada a capitales estadounidenses, y la Royal Dutch Petroleum, ingleses) y apelaban a una lucha fraterna de clases en defensa de los trabajadores bolivianos y paraguayos contra los jefes y oficiales; o, en otros términos, a la fraternización con el ejército enemigo: "confraternizar con los soldados y transformar la guerra entre países en una guerra civil entre clases sociales opuestas" (29), expresaban, por ejemplo.

En un sentido con matices similar, en la denuncia del ensayo testimonial y vivencial de González Tũón sobre el crimen que implica una contienda entre hermanos, los culpables también son los intereses imperiales, aunque el poeta argentino sostiene, como decíamos antes, una simpatía o inclinación por Paraguay (en una línea muy cercana a la que propugnaban también los intelectuales de Claridad) que lo distancia, entonces, en ese punto, de algunas de las posiciones más o menos generales de los comunistas, que criticaban este apoyo, tal como consigna Hernández. De esta manera, y si bien mantiene una visión del "imperialismo" en gran medida bastante fragmentaria, porque acusa casi excluyentemente a los capitales imperiales bolivianos, con olvido de mencionar los de Paraguay —donde también influían intereses económicos argentinos, como se ha estudiado - (Hernández), su postura empalma de todos modos con la esbozada en algunas publicaciones de los comunistas, porque también remarca (en una "fraternidad" representada insistentemente en las notas y referida una y otra vez), la paridad querida y deseada de los soldados en ofensiva de dos pueblos débiles que combaten, en realidad, contra un enemigo poderoso que está afuera. Ciertamente, si bien González Tuñón apoya afirmativa y manifiestamente a Paraguay, en la línea del diario, sus notas muestran tensiones textuales que se dejan leer como artimaña del ensayista y que apuntan a la construcción de cierta hermandad que busca equiparar en el horror bélico a los soldados paraguayos y a los bolivianos. Estas oscilaciones y cuestionamientos de la visión expresada en muchas zonas ensayísticas sobre la guerra del Chaco pueden verse claramente, por ejemplo, en los epígrafes que se inscriben en algunos de los capítulos de las notas, donde se reproducen partes de la "Canción de la pequeña brigada", fragmentos de un poema que con reelaboraciones se retomarán en los versos sobre el Chaco incluidos en Todos bailan. Puede leerse, así, un sutil distanciamiento en la apreciación de González Tuñón mediante el que discute la visión del diario defensora enfática de Paraguay: "Del otro lado, en la trinchera / enemiga, también están / la sed, el hambre, el sueño. Espera / tu sucio pedazo de pan".

En la construcción de esta hermandad que se intensifica y se refuerza entonces en el poema posterior de Todos bailan - " ${ }^{6}[\mathrm{c}]$ Hemos oído la guerra hermanos? 
/ Hemos visto la guerra hermanos? / [...] Seremos hermanos, hermanos / algún día tendrá que ser" (Todos bailan 190)-, se muestra elocuentemente (como se ve en este fragmento) que acá no hay preferencias sinceras por ningún frente, todos padecen por igual, el hambre y el dolor nivelan. Esta perspectiva tiene que ver también, por lo demás, con la que González Tuñón había expresado unos meses antes en su columna de las contratapas de Crítica "Parece mentira", antes de viajar como enviado especial del diario: "La guerra entre Bolivia y Paraguay ha sido decretada por el capitalismo de ambos países. Son los intereses encontrados de poderosas empresas los que arrastran al asesinato a dos pueblos infelices" (25 de julio de 1932: 20).

Puede decirse entonces que en estos textos de guerra se evidencian fluctuaciones significativas en la delimitación de la figura autoral de González Tuñón y vacilaciones reveladoras. En efecto, el deslizamiento de una cierta insinceridad ideológico-política estratégica en la crónica del corresponsal es un punto ensayístico de esa prosa, una trampa que la literatura les hace a los presupuestos comunicativos del periódico: ¿ $\mathrm{La}$ voz que leemos piensa como Crítica o como quién? El diario funciona en más de un sentido como espacio de configuración, línea transicional y laboratorio del viraje político, literario e intelectual de González Tuñón. La guerra del Chaco ensayada en las corresponsalías de González Tuñón permite examinar, así, algunas de las claves de ese giro, un aprendizaje del cronista que en años subsiguientes otros textos expanden, congregan y profundizan. En los vaivenes de esa escritura ensayística suscitada en el diario se lee una de las primeras manifestaciones del viajero de acción política y del intelectual comprometido y sus notas permiten mostrar la complejidad que se nos presenta al pensar los ensayos en sus diversos contextos enunciativos. Pero, además, el ejemplo de González Tuñón resulta más que explicativo para revisar algunas restricciones y resistencias de las conceptualizaciones del "ensayo como forma". La elección de un autor que, como se sabe, no es considerado ensayista a todas luces y el recorte en torno a textos ubicados en la heterogeneidad de la prensa diaria, permiten reflexionar acerca de la conveniencia crítica de asumir una noción más plástica sobre el ensayo, que abarque también estos casos más misceláneos vinculados a la crónica de los escritores y a la prosa periodística; textos ciertamente de mezcla, aquí se asume por momentos la especulación del ensayo y la discusión de ideas escritas por parte de un sujeto que enfrenta no solamente un objeto "preformado culturalmente", sino además a un marco reconocido de discursividad, publicación y exposición, difusión masiva y circulación social. Ensayos heterogéneos, híbridos, polimorfos y ciertamente polifónicos, que por supuesto parece necesario incluir en toda perspectiva que se proponga pensar los modos del ensayo o reflexionar sobre un tipo 
de ensayo - (iotra forma?) - capaz de introducir en contextos de publicación comunicacionales, pragmáticos y comerciales las vacilaciones, los deslizamientos de incertidumbre y la suspensión de los sentidos que permiten detectar los huecos de los discursos sociales, sacar a escena las lagunas de las representaciones culturales y dar a sospechar sobre lo pensado y lo no pensado. Como en el caso de estos textos de González Tuñón, un yo ensayante sopesa a la vez el tema de su escrito y la inconsistencia probable, conjetural o ya parcialmente aprovechada, del periodismo comercial y sus circuitos y efectos.

\section{Jorge Luis Borges y los circuitos de la reflexión del ensayo}

Una de las operaciones críticas muy sugerentes del libro de Alberto Giordano consiste en examinar en el ensayo particular de Borges, y siguiendo su modelo de praxis lectora, esos detalles suplementarios que "atraen la atención del lector" y permiten iluminar "el sentido de la totalidad de la obra" de un autor. Para ello, y a partir del recuerdo metodológico "de esta enseñanza de Borges ensayista", en uno de sus primeros capítulos se propone "releer la totalidad virtual de su obra crítica desde un texto absolutamente marginal y anecdótico" (10) aparecido en la revista Contra, que el crítico retoma, según refiere, a partir de una investigación sobre las funciones de la literatura en el discurso de las revistas argentinas de izquierda durante los años veinte y treinta. Se trata de la respuesta de Borges a una encuesta propuesta por Contra y titulada " ${ }_{\mathrm{C}} \mathrm{El}$ arte debe estar al servicio del programa social?". Al considerar este texto ensayístico, el análisis de Giordano no se detiene en las cuestiones vinculadas con el carácter circunstancial de esa intervención borgeana y la particularidad (no menor, claro está) de ser un texto publicado nada más y nada menos que en una revista como Contra; en cambio, Giordano se orienta hacia una frase final de ese ensayo de Borges: "Todos ya saben que este es un misterioso universo, pero muy pocos de esos todos lo sienten". Esta sentencia, en cuanto detalle marginal significativo, para Giordano, es la que invita a la revisión iluminadora de la obra crítica de Borges - en el sentido de que instaura "un nuevo punto de vista para pensarla" (9)—. Es más, a juicio de Giordano, "atrae hacia una realidad extraña a la lógica de las batallas por la legitimidad y el prestigio", y añade:

[...] en esta frase hay un eco de la más insistente afirmación que recorre los ensayos borgeanos: la del misterio de la eficacia estética. [...] Borges sostiene que el crítico no se debe dejar inhibir por supersticiones profesionales, si quiere experimentar "la eficacia o la ineficacia de una página", sino que debe perseverar en su posición de lector, "en el sentido ingenuo de la palabra". La ética del ensayista, la que se afirma incluso en los márgenes más inesperados 
de las intervenciones críticas, es la del lector ingenuo o inocente, la del que solo escribe aun cuando responde a las demandas culturales, sobre lo que aumenta su potencia de pensar, imaginar e interrogarse, de experimentar en la escritura su legítima rareza. (18)

Más allá de que el propio crítico defina y proyecte a partir de lo que lee en ese episodio de Borges su propia propuesta y estimación del modo de funcionamiento "eficaz" de la indagación literaria (la que él como teórico y ensayista pretende llevar a cabo), como puede verse claramente, esa sentencia no parece dejar entrever algo tan insospechado en Borges o un punto de vista que no pudiese preverse, tal como él parece proponer, sino que resulta imprevista en ese contexto. Si esa frase es, por lo demás, como afirma Giordano, un "eco de la más insistente afirmación que recorre los ensayos borgeanos", ¿cuál es la extrañeza no sabida o no evidente sobre Borges que ofrece esta disimulada sentencia, más allá de haber sido encontrada, como un hallazgo inesperado, en un texto impensado

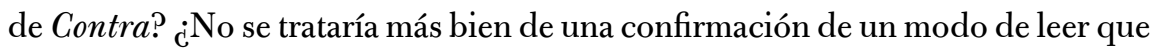
Giordano propone como efectivo siguiendo el modelo de Borges?

Podría sostenerse, más específicamente, en cambio, que ese tipo de "revisiones de la totalidad de una obra" a la que invitan los textos ensayísticos no dependen solamente de cuestiones como las que examina y prioriza Giordano, sino que, además, si se pone el foco en el carácter contingente y eventual que se vincula con los espacios de publicación de los textos o con los sitios a partir de los cuales los escritos ensayísticos transitan y se gestan, también pueden leerse correlativamente y con insistencia en el ensayo, variados y no menores hallazgos o contextos que se vuelven, en muchos sentidos, iluminadores, explicativos y hasta elocuentes a veces como casos o ejemplos. Lo circunstancial asociado a los lugares de producción ensayísticos permite un acercamiento significativo, diverso y plural a la obra de un autor y consiente en revisar, más allá de los detalles suplementarios que puedan aparecer y también dar cuenta, expresivamente, de esa escritura, los vaivenes y fluctuaciones que manifiestan su complejidad y polifonía. Para mostrar la efectividad polifacética y variada de una lectura del ensayo en el cruce e intersección con sus espacios de circulación (variada en relación con la carga de información que ofrece para repensar la obra de un autor, interrogarla y exponer sus vaivenes nunca simples), es preciso reconsiderar la anécdota de la doble publicación en Sur y en El Hogar de los artículos de Borges sobre Miguel de Unamuno con que se inicia este artículo.

En el contraste y la comparación entre estos dos textos publicados en revistas tan distintas, varias cuestiones pueden visualizarse y ponerse de manifiesto. 
En "Inmortalidad de Unamuno", el texto aparecido en Sur el 28 de enero de 1937, Borges analiza la cuestión de la inmortalidad a la que convoca la muerte de todo escritor, un "problema - para él- de naturaleza dramática", ya que dramáticamente "persiste el hombre general (nuestra imagen del hombre general) o desaparece", y considera el hecho de que "en el caso de Miguel de Unamuno hay el riesgo certero de que la imagen empobrezca irreparablemente la obra" (Borges en Sur 143). Al día siguiente, como dijimos, publica en el semanario ilustrado El Hogar, "Presencia de Miguel de Unamuno", un texto ensayístico notoriamente más largo que el anterior en el cual va recorriendo y evaluando, con sarcasmo e ironía crítica, distintas zonas de la producción de Unamuno. El movimiento de Borges allí se propone mostrar cómo leer en esos textos (y también en algunos de los "versos fallidos" del español), la omnipresencia de un yo: o, dicho en otros términos, el modo en que la figura (la imagen de un creador) se sobrepone a una obra (como había sostenido en la tesis de Sur): "La presencia, discutidora, gárrula, atormentada y a veces intolerable", del "primer escritor de nuestro idioma", "está con nosotros" a través de sus textos, y ello a pesar de que ante muchos de ellos el ensayista sienta "la vasta incomodidad del hombre que sorprende, sin querer, un secreto ridículo de una persona que aprecia" (Borges, Textos cautivos 249-250).

Además del ejercicio irónico y eficaz de la ambigüedad que se inscribe en estos artículos sobre Unamuno, los dos textos pueden pensarse como una escritura o sobreescritura (en el sentido de escribir sobre algo ya escrito) de la misma tesis sobre Unamuno - la tesis de que en su ausencia, con su muerte, la figura fuerte sobrepasará a su obra disímil e impar-. Ahora bien, más allá de las coincidencias, interesa reparar en algunas disimilitudes que también pueden atribuirse a decisiones que ha tomado Borges respecto de los divergentes contextos de enunciación, como se sabe, diversos y en más de un sentido, antagónicos. La intervención de Borges en Sur parte de premisas un tanto incontrovertibles o que el ensayista no repara en discutir ni en indagar, surge de una idea preliminar que se ensaya sin dilaciones ni argumentos medulares y con un salto condescendiente a otros posibles presupuestos. En la nota ensayística aparecida en El Hogar, una revista dirigida, como se sabe, al consumo femenino, a la lectora doméstica, para su gratificación y esparcimiento, ${ }^{13}$ la intensidad y el impulso se vuelcan, más allá

13 Como muchas de las publicaciones surgidas a principios del siglo Xx, El Hogar se dirigió inicialmente a un público masivo que adoptaba de manera creciente nuevos consumos culturales al calor de los procesos de modernización. Para diferenciarse, su director editorial, Alberto Haynes, decidió que esta revista apelaría a las consumidoras, especialmente a la lectora doméstica. En la línea de las publicaciones destinadas al público femenino desde el siglo XIX, 
del interés en la exposición de una idea, en el desarrollo argumentativo, que se aúna en este caso a la demostración y exposición lectoras por parte del ensayista y a un recorrido casi difusionista por la biblioteca leída de Unamuno que Borges refiere y recuerda. Mientras que en Sur la misma idea ambivalente sobre Unamuno se expresa en un tono más deliberativo y filosófico, con un entramado conceptual y más urdido y complejo, el ensayo de El Hogar prolifera en citas de sus textos y en ejemplos que luego se condensan en una idea al final.

Con solo mirar, a su vez, los índices de las notas que Borges edita entre mediados de los años treinta y los primeros cuarenta en El Hogar y Sur (nos circunscribimos a los efectos de las comprobaciones de este artículo a los textos publicados por Borges en este periodo, porque es el momento en el que tiene mayor producción en El Hogar, pero puede ampliarse esta consideración a otros momentos, otros circuitos y otros espacios) allí puede constatarse una insistente coincidencia. Borges escribe sobre temas afines, autores y preferencias estéticas y literarias en las dos publicaciones y en muchos casos aparecen ensayos y textos críticos sobre una misma cuestión puntual suscitada, eventualmente, por el contexto de enunciación, la publicación reciente de un libro o, como en el caso de Unamuno, la muerte del escritor, entre otras variables. Esto permite enunciar una hipótesis preliminar sobre la diversa y disímil participación de Borges en $E l$ Hogar y Sur y los vaivenes de su escritura ensayística (que no se va a desarrollar exhaustivamente aquí, sino que solamente se esboza para mostrar la productividad de pensar el ensayo en sus contextos). Si en muchos ensayos de Sur parece sostenerse una especie de ensamble de lo que se ha considerado un laboratorio para la ficción borgeana y un espacio urdido e intelectual, en el que promueve y polémicamente defiende sus ideas sobre la ficción narrativa, la literatura, la especulación y las formas del ser escritor, El Hogar se va instituyendo, en cambio, como una zona más amplia, lábil y diversa en Borges. Allí, a la vez que va delimitando su biblioteca, una biblioteca abigarrada y compleja que se constata y contrasta con el público lector, muchas veces femenino de la publicación, parece orientarse a cierto interés en la divulgación y difusión lectora. Borges promueve

pero al mismo tiempo, en el contexto periodístico que impone el formato magazine - con la irrupción de la miscelánea como norma que combina información y entretenimiento, placer y consumo - El Hogar establece en sus páginas un espacio distintivo tanto para el consumo entendido como gratificación y esparcimiento (Félix Didier y Szir) como para la "ilustración" de la mujer, incluyendo en este concepto tanto la provisión de una didáctica para el hogar (tutelando las normas de configuración de la femineidad, el cuidado de los niños, proveyendo información sobre la economía doméstica en un sentido amplio, la sociabilidad femenina) como el acceso a textos literarios y artísticos como complemento de esas pedagogías. 
activamente sus lecturas y define, así, en la prensa cultural y periódica no solamente sus ideas sobre la narración y lo literario, sino también enseña y ensaya en la revista femenina El Hogar (pone a prueba y evalúa) la efectividad de su biblioteca, de aquella que está armando como lector y que está en la base, ciertamente, de muchas de sus reescrituras y revisiones.

Como puede verse en el ejemplo de Unamuno, los vaivenes de la ensayística borgeana parecen mostrar que mientras en Sur las maniobras de la escritura se orientan a un oponente y un lector con el que Borges, subrepticia y probablemente pretendería discutir y polemizar, en El Hogar, el ímpetu del ensayo y su carácter más ejemplificador, esquematizante y argumentativo, parece empalmar con una apelación a ese público (masificado, más anónimo y en muchos sentidos plural de la revista) al que Borges, podría sostenerse, buscaría (más allá de convencer) edificar y educar en torno a un núcleo de lecturas y a una biblioteca que es la de sus propias preferencias. Esto inscribe de algún modo en la labor ensayística de Borges, las marcas de un autor que lejos de desinteresarse por los efectos de sus textos en el lector masivo y diverso de la cultura impresa que se abre en el siglo XX, lo sopesa (deliberadamente o no) en las formas variadas de la construcción ensayística.

\section{Obras citadas}

Adorno, Theodor. "El ensayo como forma". Notas de literatura. Barcelona: Ariel, 1962. Impreso.

Agamben, Giorgio. “¿Qué es lo contemporáneo?”. Desnudez.

Buenos Aires: Adriana Hidalgo, 2011. Impreso.

Arias Saravia, Leonor. La Argentina en clave metafórica: un itinerario a través del ensayo. Buenos Aires: Corregidor, 200o. Impreso.

Boletín del Centro de Estudios de Teoría y Crítica Literaria. Número dedicado a "El ensayo de los escritores". Rosario 9 (diciembre 2001). Impreso.

Boletín del Centro de Estudios de Teoría y Crítica literaria. Número dedicado a "Políticas del ensayo". Rosario 10 (diciembre 2002). Impreso.

Borges, Jorge Luis. Borges en El Hogar: 1935-1958. Buenos Aires: Emecé, 200o. Impreso. Borges, Jorge Luis. Borges en Sur: 1931-1980. Buenos Aires: Emecé, 1999. Impreso.

Borges, Jorge Luis. Textos cautivos: obras completas IV.

Buenos Aires: Emecé, 1996. Impreso.

Chevalier, Tracy, ed. Enciclopedia of the Essay. London:

Fitzroy Dearborn Publishers, 1997. Impreso.

Félix Didier, Paula y Sandra Szir. "Ilustrando el consumo: la relación textoimagen en los avisos de publicidad gráfica aparecidos en las publicaciones 
periódicas en Buenos Aires (1898-1910)". Documento procedente del I Congreso Internacional de Teoría e Historia de las Artes-IX Fornadas CAIA. Poderes de la Imagen. Buenos Aires: CAIA, 2001. CD-ROM.

Ferrari, Germán. Raúl González Tuñón periodista. Buenos Aires: Centro

Cultural de la Cooperación Floreal Gorini, 2006. Impreso.

Flawiá de Fernández, Nilda. El ensayo argentino, 1900-1950. Tucumán: Instituto de Investigaciones Lingüísticas y Literarias Hispanoamericanas, 1988. Impreso.

González Tuñón, Raúl. "Camino a isla Poi: capítulo II".

Crítica 20 de octubre de 1932: 9. Impreso.

González Tuñón, Raúl. "El Chaco sale a recibirnos: Palo Santo.

Capítulo IV". Crítica 21 de octubre de 1932: 9. Impreso.

González Tuñón, Raúl. "El error de Bolivia: capítulo XIV".

Crítica 28 de octubre de 1932: 9. Impreso.

González Tuñón, Raúl. "El zapato agujereado en el talón: capítulo VIII". Crítica 24 de octubre de 1932: 11. Impreso.

González Tuñón, Raúl. "En la guarida del alto comando: capítulo VII". Crítica 23 de octubre de 1932: 11. Impreso.

González Tuñón, Raúl. "Isla Poi o la puerta infernal: capítulo V". Crítica 22 de octubre de 1932: 9. Impreso.

González Tuñón, Raúl. "La aventura de Puerto Pinasco: capítulo III". Crítica 21 de octubre de 1932: 9. Impreso.

González Tuñón, Raúl. "La ruta de la muerte y la victoria: capítulo IX". Crítica 24 de octubre de 1932: 11 y 12. Impreso.

González Tuñón, Raúl. "La vuelta por el mismo camino: capítulo XIII". Crítica 27 de octubre de 1932: 11. Impreso.

González Tuñón, Raúl. "Las guitarras de Isla Poi: capítulo XII". Crítica 27 de octubre de 1932: 11. Impreso.

González Tuñón, Raúl. "Los campos trágicos de Boquerón: capítulo VI". Crítica 22 de octubre de 1932: 9 y 16. Impreso.

González Tuñón, Raúl. "Los cuatro jinetes del Apocalipsis: capítulo XI". Crítica 26 de octubre de 1932: 9. Impreso.

González Tuñón, Raúl. "Muerto por la señora Standard: capítulo X". Crítica 25 de octubre de 1932: 11. Impreso.

González Tuñón, Raúl. "Sobre los techos de Asunción: capítulo 1". Crítica 19 de octubre de 1932: 3. Impreso.

González Tuñón, Raúl. La calle del agujero en la media: todos bailan. Buenos Aires: Espasa Calpe, 1993. Impreso. 
Giordano, Alberto. Modos del ensayo: de Borges a Piglia.

Rosario: Beatriz Viterbo, 2005. Impreso.

Gómez-Martínez, José Luis. Teoría del ensayo. México: UNAM, 1992. Impreso.

González, Horacio. Restos pampeanos: ciencia, ensayo y política en la cultura argentina del siglo XX. Buenos Aires: Colihue, 1999. Impreso.

Heinich, Nathalie. Être écrivain: création et identité.

Paris: La Découverte, 2000. Impreso.

Hernández, Juan Luis. "Debates sobre la Guerra del Chaco: anarquistas y comunistas, Nervio y Correspondencia sudamericana". Del antifascismo a la guerra fría: prensa política y revistas latinoamericanas de los '30 y '40. Actas de las IV fornadas de Historia de las Izquierdas. Buenos Aires: CeDinCi, 2007. 19-30. Impreso.

Juárez, Laura. "Arlt y la polémica sobre la novela". Revista Iberoamericana 222 (2008): 13-31. Impreso.

Juárez, Laura. "Raúl González Tunoón 'en las alas de Crítica': crímenes y 'aventuras' heroicas en la guerra del Chaco". Aletria. Revista de Estudos de Literatura 23.1 (2013): 97-110. Impreso.

Louis, Annick. Forge Luis Borges: oeuvre et manoeuvre. Paris: L'harmattan, 1997. Impreso.

Lukács, Georg. "Sobre la esencia y forma del ensayo". El alma y las formas: teoría de la novela. México: Grijalbo, 1971. Impreso.

Mattoni, Silvio. Las formas del ensayo en la Argentina de los años '50. Córdoba: Universitas, 2003. Impreso.

Montaigne. Essais. Tome I. Paris: Garnier Frères, 1962. Impreso.

Pastormerlo, Sergio. Borges crítico. Buenos Aires: Fondo de Cultura Económica, 2007. Impreso.

Rest, Jaime. El cuarto en el recoveco. Buenos Aires: CEAL, 1982. Impreso.

Rosa, Nicolás, ed. Historia del ensayo argentino: intervenciones, coaliciones, interferencias. Buenos Aires: Alianza, 2002. Impreso.

Rotker, Susana. La invención de la crónica. Buenos Aires: Letra Buena, 1992. Impreso.

Roy, Joaquín. Periodismo y ensayo. Lleida: Edicions de la Universitat de Lleida, 2000. Impreso.

Saítta, Sylvia. "Modos de pensar lo social: ensayo y sociedad en la Argentina (1930-1965)". Eds. Federico Neiburg y Mariano Plotkin. Intelectuales y expertos: la constitución del conocimiento social en la Argentina. Buenos Aires: Paidós, 2004. 107-146. Impreso.

Saítta, Sylvia. "Polémicas ideológicas, debates literarios". Contra. La Revista de los Franco Tiradores (2005): 13-33. Impreso. 
Saítta, Sylvia. Regueros de tinta. El diario. Crítica en la década de 1920. Buenos Aires: Sudamericana, 1998. Impreso.

Sarlo, Beatriz. "Del otro lado del horizonte". Boletín del Centro de Estudios de Teoría y Crítica Literaria 9 (2001). Impreso.

Sarlo, Beatriz. Una modernidad periférica. Buenos Aires: Nueva Visión, 1988. Impreso.

Sonderéguer, María. "Avatares del nacionalismo". La irrupción de la crítica. Dir. Susana Cella. Tomo 10 de Historia crítica de la literatura argentina. Buenos Aires: Emecé, 1999. Impreso.

Starobinsky, Jean. “Es posible definir el ensayo?". Cuadernos Hispanoamericanos 575 (mayo 1998). Impreso.

Starobinsky, Jean. "Les enjeux de l'essai". Hacer la historia. Vol. II: Nuevos enfoques. Eds. Jacques Le Goff y Pierre Nora. Barcelona: Laia, 1979. Impreso.

Weinberg, Liliana. El ensayo, entre el paraíso y el infierno. México: Fondo de Cultura Económica, 2001. Impreso.

Weinberg, Liliana. Pensar el ensayo. México: Siglo XXI, 2007. Impreso.

Weinberg, Liliana. Situación del ensayo. México: Universidad Nacional Autónoma de México, 2006. Impreso. 